\title{
Effect of Training on Knowledge Level of Farmers About Commercial Poultry and Table Egg Production
}

\author{
Eva Palada*, Ernesto Alde and Ruel Delantar \\ Eastern Samar State University, Philippines
}

\begin{abstract}
Article Type: Article
Article Citation: Eva Palada, Ernesto Alde, Ruel Delantar. Effect of training on knowledge level of farmers about commercial poultry and table egg production. Indian Journal of Science andTechnology.2020;13(06),646-653.D01: 10.17485/ijst/2020/v013i06/148985

Received date: November 20, 2019

Accepted date: December 31, 2019

*Author for correspondence:

Eva Palada \$ovp.pre.essu@gmail. com $\uparrow$ Eastern Samar State University, Philippines
\end{abstract}

\begin{abstract}
Objectives/methods: The study assessed the effect of training on commercial poultry and table egg production on the knowledge level of farmers. Two training sessions were conducted in Oras and San Policarpo, Eastern Samar in the same venue and by the same team of resource persons that was participated by 200 farmers identified as beneficiaries of the SAAD program of the Philippine government. The topics covered during each of the two-day training session were on house construction, production management, feeding, health and sanitation, poultry farms and the environment, and record keeping and marketing. The knowledge level of the farmers was indicated by the scores they obtained during the pre-test and post-test administered immediately before and after the training. Findings/application: The results of the study revealed that there was a significant difference in the knowledge level of the farmers before and after the training $(t=8.009, p=0.000)$. The change in the knowledge level of the farmers due to the training on commercial poultry and table egg production was $33.14 \%$ on the average, and the effect size of the training was found large (ES = 1.22). Sex, age, and education were found to have no significant influence on the percent change in knowledge level among the farmer-respondents. It may be concluded from the study that the training on commercial poultry and table egg production has resulted a significant effect on the knowledge level of the farmers.
\end{abstract}

Keywords: Knowledge Level, Training Effect Size, Eastern Samar Farmers.

\section{Introduction}

One of the overall long-term goals of the Philippine Government under the administration of President Duterte as embodied in Executive Order No. 05 or the Ambisyon Natin 2040 is to eradicate hunger and poverty by [1]. This Order directs government departments, 
offices, and instrumentalities to be guided by and adopt the vision of Ambisyon Natin 2040 in their development planning.

Anchored on the development agenda of Ambisyon Natin 2040, the Department of Agriculture (DA) through its Regional Field Offices is implementing the Special Area for Agricultural Development (SAAD) Program to contribute in the reduction of poverty and the attainment of food security of farmers in the priority provinces. The SAAD program is composed of four major components [2]: 1) Program Management, 2) Social Preparation, 3) Production and Livelihood Interventions, and 4) Marketing Assistance and Enterprise Development. The Social Preparation component encompasses the series of trainings (including needs assessment) in order to ensure readiness and the empowerment of SAAD beneficiaries in accepting and managing the interventions been provided by the program, while the latter entails livelihood projects to be given based on the assessed needs of the recipients (http://saad.da.gov.ph).

Through the SAAD program, a total of 30 provinces shall have been given assistance in both agriculture and fisheries. The province of Eastern Samar is one of the priority provinces under SAAD Program being one of the poorest provinces. In Eastern Samar, the Eastern Samar State University (ESSU) is qualified and capable to support the SAAD program through the conduct of appropriate education, extension, and training services. Thus, the Regional Field Office No. 8 of the Department of Agriculture has forged Memorandum of Agreement on August 23, 2017 with ESSU for the implementation of the project "Extension Support, Education, and Training Services for Poor Estehanons (ESETS for PoorEST)". With this partnership, ESSU through the College of Agriculture and Natural Sciences shall take part in the Social Preparation component by implementing training in identified food production projects to farmer-beneficiaries of the SAAD program in ten municipalities in the province of Eastern Samar, namely, Jipapad, Maslog, Arteche, San Policarpo, Oras, Dolores, Balangkayan, Hernani, Gen. Macarthur, and Quinapondan for a total of 100 beneficiaries per municipality.

One of the identified food production projects which ESSU has conducted training to farmers is on commercial poultry and table egg production. To determine whether the training has an effect on the knowledge level of the farmer-beneficiaries, this study was conducted.

\subsection{Statement of the Problem}

The study assessed the effect of training on commercial poultry and table egg production on the knowledge level of farmers.

Specifically, the study answered the following questions:

1. How do the farmers distribute themselves in their knowledge level before and after the training?

2. Is there a significant difference in the knowledge level of the farmers before and after the training?

3. What is the effect size of the training?

4. What is the distribution of the farmers according to gain in knowledge due to the training? 
5. Do sex, age, and education influence the gain in knowledge of farmers due to the training?

\subsection{Hypotheses of the Study}

The study tested the following null hypotheses at $\alpha=0.05$ :

There is no significant difference in the farmers' knowledge on commercial poultry and table egg production before and after the training.

Farmers' sex, age, and education do not significantly influence their gain in knowledge on commercial poultry and table egg production due to the training.

\section{Methodology}

The study was a quasi-experimental research following the one-group pretest-postest design. In the one-group pretest-posttest design of experimental research [3], explain: a single group is measured or observed not only after being exposed to a treatment of some sort, but also before. The treatment in this study was the two-day training on commercial poultry and table egg production. The subject of this study was the purposively selected 200 farmers being beneficiaries of the SAAD program, 100 each from two of the ten identified municipalities of the Eastern Samar province.

The training was conducted following the same protocol in two nearby municipalities situated in the northern part of the Eastern Samar province, Oras in August 17 and 18, 2019 and in San Policarpo in August 24 and 25, 2019.

The two-day training consisted of lecture-discussions using power point presentations. Five topics were covered in the training that included House Construction, Production Management, Feeding, Health and Nutrition, Poultry Farms and the Environment, and Record Keeping and Marketing, which were discussed by the same team of four resource persons. The two trainings were conducted in the same venue and the same time schedule was followed throughout the duration of the training.

A 20 -item test of the multiple choice type covering the five topics was prepared by the researchers in consultation with the resource persons to measure the knowledge of the subject matter or content of the training. Pre-test was administered before the start of the training session during the first day and the post-test before the closing program of the second day. The same person administered the tests in both locations of the training. The farmers were briefed properly on what to do before each test was given. In addition, the farmers were asked to write their names, sex, age, and highest level of education attained which were considered as moderator variables in this study. Scoring of the test was done manually.

The following procedures were followed in the analysis of the data.

The knowledge level of the farmers on commercial poultry and table egg production was indicated by their total scores on the test. 
To determine if a significant difference was observed in the knowledge level of the farmers before and after the training, paired $t$-test was used and the test of significance was set at $\alpha=0.05$.

The gain in knowledge due to the training on commercial poultry and table egg production was the difference between the post-test and pre-test scores divided by the pre-test score and the result was multiplied by 100 to express this in percent. This is also percent change in knowledge.

The effect size or magnitude of effect of the training on the knowledge about commercial poultry and table egg production was calculated using the computational equation patterned after. This computation is used if the two groups have the same $n$ or a number of cases, and the resulting effect size is called $d_{\text {Cohen }}$ and it is used for calculating the effect for pre-post comparisons in single groups. Moreover, the calculated effect size was described using Cohen's criteria of interpretation [4] as follows.

\begin{tabular}{ll}
\hline Value & Interpretation \\
\hline $0.00-0.20$ & Small effect \\
$0.21-0.79$ & Medium effect \\
$>0.80$ & Large effect \\
\hline
\end{tabular}

To find out whether sex, age, and education influence the gain in knowledge of farmers due to the training, multiple regression analysis was performed and test of significance was set at $\alpha=0.05$.

\section{Results and Discussion}

\subsection{Knowledge Level of Farmers on Commercial Poultry and Table Egg Production Before and After the Training}

Table 1 compares the knowledge level of the farmers who attended the training on commercial poultry and table egg production before and after the training. The data in Table 1 reveal that, before the training, about $83 \%$ of the 200 farmers scored half of the test and this proportion of farmers was increased to $99 \%$ after the training. On the average, the farmers scored 11 in the 20 -item test during the pre-test and it was increased by 3 points after the training. Moreover, the data in Table 1 show that the knowledge level of the farmers about commercial poultry and table egg production was normally distributed as indicated by the score of 11 for the mean, median, and mode during the pre-test and the score of 14 for the mean, median, and mode during the post-test.

The result of the paired $t$-test gave a computed $t$ value of 8.009 with a $p$ value of 0.000 (Table 1). This result suggests that there is a significant difference in the farmers' knowledge on commercial poultry and table egg production before and after the training. Hence, the first null hypothesis of this study was not accepted. This result clearly indicates that the training has a significant effect on the knowledge level of the farmers, that is, the training helps in increasing knowledge of respondents. This result of the study corroborates the 
Effect of Training on Knowledge Level of Farmers About Commercial Poultry and Table Egg Production

TABLE 1. Comparison of farmer-respondents' knowledge level on commercial poultry and table egg production before and after the training

\begin{tabular}{|c|c|c|c|c|c|}
\hline \multirow{2}{*}{$\begin{array}{l}\text { Knowledge } \\
\text { level (total } \\
\text { score) }\end{array}$} & \multicolumn{2}{|c|}{ Before the training } & \multicolumn{2}{|c|}{ After the training } & \multirow[b]{2}{*}{$t$ value } \\
\hline & $\begin{array}{c}\text { Frequency } \\
(N=200)\end{array}$ & Percent & $\begin{array}{l}\text { Frequency } \\
(N=200)\end{array}$ & Percent & \\
\hline Below 5 & 5 & 2.50 & 1 & 0.50 & \\
\hline $5-9$ & 30 & 15.00 & 1 & 0.50 & \\
\hline $10-14$ & 152 & 76.00 & 112 & 56.00 & \\
\hline 15 and above & 13 & 6.50 & 86 & 43.00 & \\
\hline Range & $4-16$ & & $4-19$ & & $8.009^{\star}$ \\
\hline Median & 11 & & 14 & & $(p=0.000)$ \\
\hline Mode & 11 & & 14 & & \\
\hline Mean & 11.35 & & 14.26 & & \\
\hline SD & 2.40 & & 2.17 & & \\
\hline SE & 0.21 & & 0.18 & & \\
\hline
\end{tabular}

*Significant at $\alpha=0.05$

finding of the study of Tayade and Chinchmaltpure [5] that the training about the use of bio-pesticide and its mass multiplication on agriculture wastage has significant and positive impact on the knowledge level of farmers as indicated by an increase in their knowledge after receiving the training.

\subsection{Farmers' Gain in Knowledge due to the Training and Effect Size of the Training}

It can be noted in Table 2 that there were farmers who were found to have not increased or gained their knowledge from the training on commercial poultry production, but there was one who was able to record a $250 \%$ increase in knowledge level due to the training received as indicated by the range values of $0-250 \%$. About 2 out of 5 farmers have up to $20.99 \%$ change in knowledge level due to the training. A great number got $38 \%$ (mode) change in knowledge, half or 100 farmers have a knowledge gain of $25 \%$ (median), and, generally speaking, the farmer-respondents have 33.14\% (mean) increase in their knowledge level before and after the training. Although there is a wide spread in the distribution of the farmer-respondents according to their gain in knowledge due to the training on commercial poultry and table egg production as indicated by the range and SD values, the result of this study yield a value of 1.22 for the effect size (ES) of the training. Using Cohen's criteria of interpretation, this means that the intervention (the training) had a large effect. Moreover, consistent with the idea of Ref. [6] on how effect sizes can be interpreted, in terms of "Common Language Effect Size" (CLES) statistic, this ES of 1.2 is translated to a CLES of 0.80 . In other words, 80 out of 100 farmers would have recorded an increase in their knowledge level due to the training.

The result of this study on the "large" effect size of training on the knowledge level of farmers confirms an earlier study by Palada et al. [7] although the study was not about farmers' knowledge. The study was about improving faculty-researchers' capability on data analysis through the conduct of a four-day training using lecture and hands-on or 
TABLE 2. Distribution of farmer-respondents according to gain in knowledge due to training on commercial poultry and table egg production and the effect size of the training

\begin{tabular}{lccc}
\hline Gain in knowledge (\%) & Frequency & Percent & $\begin{array}{c}\text { Effect size of the } \\
\text { training }\end{array}$ \\
\cline { 2 - 2 } & $\mathbf{N}=\mathbf{2 0 0}$ & & 45.00 \\
\\
\hline Up to 20.99 & 90 & 33.00 & \\
21 to 40.99 & 66 & 10.00 & 1.22 (Large) \\
41 to 60.99 & 20 & 6.00 & \\
61 to 80.99 & 12 & 6.00 & \\
81 and above & 12 & & \\
Median $=25 ;$ Mode $=15$ \& 36; Mean $=33.14$ & & \\
Range $=0$ to $250 ; \mathrm{SD}=36.76 ; \mathrm{SE}=3.46$ & & & \\
\hline
\end{tabular}

workshop. That study found the training to have a "large" effect on the knowledge about statistical analysis, which was significantly $(p<0.05)$ explained by the research experience of the faculty.

\subsection{Influence of Sex, Age, and Education on Farmers' Gain in Knowledge Acquired from the Training}

It can be observed from the data in Table 3 that the female farmers who attended the training had slightly higher mean gain in knowledge than their male counterparts. In addition, the relatively younger farmers have slightly higher mean gain in knowledge than the relatively older ones. Likewise, those who have obtained elementary education had the highest mean gain in knowledge compared to those who have secondary and college level education. However, the influence of these three variables on the gain in knowledge

TABLE 3. Influence of sex, age, and education on gain in knowledge of farmerrespondents due to training on commercial poultry and table egg production

\begin{tabular}{lcccc}
\hline Explanatory variables & $\begin{array}{c}\text { Mean gain in } \\
\text { knowledge }\end{array}$ & $\begin{array}{c}\text { Regression } \\
\text { coefficient }\end{array}$ & $\boldsymbol{t}$ & Sig. \\
\hline Sex & 25.1 & & & \\
Male & 39.3 & 0.169 & 1.779 & 0.078 \\
Female & & & & \\
Age & 37.6 & -0.08 & -0.839 & 0.403 \\
Relatively younger (up to 48 years old) & 29.3 & & & \\
Relatively older (49 years and older) & & & & \\
Education & 44.6 & & -1.05 & 0.296 \\
Elementary & 28.6 & -0.1 & & \\
Secondary & 32 & & & \\
Tertiary &
\end{tabular}

Constant $=35.580$, Std. error $=21.759, R^{2}=0.047$. 
of the farmers on account of the training on commercial poultry and table egg production they received was found not significant as suggested by their corresponding significant values that are all larger than 0.05 and the $R^{2}$ value. This finding means that there is no significant association between the gain in knowledge of the farmer-respondents due to the training and some of their personal attributes as sex, age, and education. Therefore, the null hypothesis that farmers' sex, age, and education do not significantly influence their gain in knowledge on commercial poultry and table egg production due to the training is accepted.

The result of the present study confirms what [8] has reported that the effect of age and education on change in knowledge level regarding goat farming due to specialized trainings on goat farming was not significant. Whereas, the result contradicts the results of the study conducted by Ezeibe et al. [9] which revealed that educational level, together with farming experience, income level and farm size, are highly significant at 5\% levels and positively related to the farmers' adoption of the improved poultry management practices [10].

\section{Conclusions}

The training on commercial poultry and table egg production has significant effect on the knowledge level of the farmers. Its effect size was large. However, there was insufficient evidence to conclude that the farmers' sex, age, and education have significantly influenced their change in knowledge level after the training.

\section{References}

1. Executive Order No. 05 - the Ambisyon Natin 2040. http://2040.neda.gov.ph/tag/executiveorder-no-5/. Date accessed: 27/08/2019.

2. Department of Agriculture. Special area for agricultural development. http://saad.da.gov.ph/ about-us/. Date accessed: 28/08/2019.

3. Fraenkel JR, Wallen NE. How to design and evaluate research in education. McGraw-Hill, Inc.: New York. 2015.

4. Pagano RR. Statistics for the behavioral science. Cengage Learning Asia Pte. Ltd. (Philippines Branch): Pasig City, Philippines. Second Philippine Reprint. 2011.

5. Tayade AM, Chinchmaltpure UR. Impact of training on knowledge level of farmers about the use of bio-pesticide and its mass multiplication on agriculture wastage. Agricultural Science Digest. 2016; 36(3), 212-215. https://arccjournals.com/journal/agricultural-science-digest/D-4260

6. Guide to calculating, interpreting and using effect size. www.leeds.ac.uk/educol/ documents/00002182.do. Date accessed: 10/09/2002.

7. Palada E, Rivera J, Arma E. Improving researchers' capability on data analysis. Eastern Samar State University: Borongan City. 2018.

8. Hundal JS, Singh U, Singh N, Kansal SK, Bhatti JS. Impact of training on knowledge level of goat farmers in Punjab. Haryana Veterinarian. 2016; 55(2), 47-49. https://www.researchgate. net/publication/316605724 
9. Ezeibe ABC, Okorji EC, Chah JM, Abundei RN. Impact of entrepreneurship training on rural poultry farmers adoption of improved management practices in Enugu State, Nigeria. African Journal of Agricultural Research. 2019; 9(20). http://www.academicjournals.org/AJAR

10. Bashir B, Venka. Impact of trainings on knowledge level of goat keepers and new entrepreneurs in Kerala. Indian Research Journal of Extension Education. 2017; 17(1). http://seea.org.in/ojs/ index.php/ irjee/issue/view/54 